\title{
Role of Opioidergic System in Humoral Immune Response
}

\author{
Suman Kapur ${ }^{1}$, Anuradha Pal ${ }^{1}$ and Shashwat Sharad ${ }^{2}$ \\ ${ }^{1}$ Birla Institute of Technology and Science, Pilani, Rajasthan \\ ${ }^{2}$ Center for Prostate Disease Research, Department of Surgery, \\ Uniformed Services University of the Health Sciences, Bethesda, MD, \\ India \\ ${ }^{2} U S A$
}

\section{Introduction}

The initial idea that exogenous opiates can affect immune function was first floated in 1898 when Cantacuze described the effect of opium on leukocyte phagocytosis in guinea pig model. Recently findings from several investigators (Quaglio et al., 2002; Nath et al., 2002; Georges et al., 1999; Vallejo et al., 2004; Roy et al., 2006; Somaini et al., 2008) support the role of opiates in suppressing a variety of immunological end points in opiate abusers. Endogenous opioids seem to have a physiological role in modulating the Th1/Th2 balance, by reducing Th1 and enhancing Th2 representative cytokines. Exogenous opioids, on the other hand, seem to display various different modulatory profiles on the immune function, according to the drug under consideration. In this regard, available evidence shows that while morphine and heroin are liable to attenuate the immune response, long-acting opioids that are used in withdrawal treatment, such as methadone and buprenorphine, are largely devoid of immunosuppressive activity. Opioids can also influence the immune function through the activation of the descending pathways of the hypothalamus-pituitary axis (HPA) and the sympathetic nervous system (Vallejo et al., 2004). This review on role of opioidergic system in humoral immune response summarizes the effect of opiate receptor polymorphism on innate and adaptive immunity, identifies the role of the mu opioid receptor in these functions, and finally discusses how changes in these parameters may increase the risk for opportune infections in drug dependent subjects or attenuate the symptoms of rheumatoid arthritis.

\section{Immune system and immune response}

The immune system is composed of many interdependent cell types that collectively protect the body from bacterial, parasitic, fungal, viral infections and from the growth of tumor cells. Many of these cell types have specialized functions. The cells of the immune system can engulf bacteria, kill parasites or tumor cells, or viral-infected cells. The immune system protects us from potentially harmful substances by recognizing and responding to their presence, invoking a specific and targeted response. An immune response is thus the mechanism by which the body recognizes and defends itself against foreign or non-self 
substances and organisms such as bacteria, viruses, and other substances that appear harmful to the body. Taken together these substances are known as antigens and the immune system recognizes and destroys substances that contain any antigens.

Immune system works as a layered defence system of increasing specificity. It can be divided into two major components:

- The Innate immune system forming the first line of defence providing an immediate, non-specific response (Litman et al., 2005)

- The Adaptive immune system, which becomes activated in case of failure/inadequacy of the innate immunity to contain the infection, recognizes the pathogen mounting a specific response, leading to formation of an immunological memory, enabling a stronger and faster response each time this pathogen is re-encountered (Mayer, 2006) in the life course of the individual.

The role of innate and adaptive immunity is tabulated below:

\begin{tabular}{|l|l|l|}
\hline Function/Immunity & Innate & Adaptive Immunity \\
\hline Kinetics & Immediate & Delayed \\
\hline Nature of Response & Non -Specific & Specific \\
\hline Cells Types Involved & $\begin{array}{l}\text { Leucocytes : NK cells, } \\
\text { Basophils, Mast cells }\end{array}$ & Lymphocytes: T-cells and B-cells \\
\hline Immune memory & $\begin{array}{l}\text { No immunological memory } \\
\text { on exposure }\end{array}$ & $\begin{array}{l}\text { Immunological memory is } \\
\text { generated on exposure }\end{array}$ \\
\hline $\begin{array}{l}\text { Receptor } \\
\text { Reorganization }\end{array}$ & $\begin{array}{l}\text { Limited number of target } \\
\text { conserved domains }\end{array}$ & $\begin{array}{l}\text { Larger number of both } \\
\text { conserved and novel domains }\end{array}$ \\
\hline
\end{tabular}

Table 1. Differences between Innate and Adaptive immunity

An immune response to foreign antigen requires the presence of an antigen-presenting cell (APC), (usually either a macrophage or dendritic cell) in combination with a B cell or T cell. When an APC presents an antigen on its cell surface to a B cell, the B cell is signalled to proliferate and produce antibodies that specifically bind to that antigen and become an agent for removal of the antigen from the host organism.

\section{Humoral response and its role}

Humoral immunity is so named because it involves substances found in the humours, or body fluids. It is mediated by antibodies produced by cells of the B lymphocyte lineage. B cells, activated by the adaptive immune responses, transform into plasma cells which secrete antibodies. This process is aided by CD4+ T-helper 2 cells, which provide active co-stimulation. The secreted antibodies bind to antigens present on the surfaces of invading microbes, which marks them for subsequent destruction (Pier et al., 2004). Another important function of antibodies is to initiate the "complement destruction cascade." 
Antibodies are glycoproteins belonging to the molecular superfamily of immunoglobulins which are often used interchangeably. In structure, they are large Y-shaped globular proteins and are classified into five types: $\operatorname{IgA}$, IgD, IgE, IgG, and $\operatorname{IgM}$. Each immunoglobulin class differs in its biological properties in targeting different types of antigens (Pier et al., 2004). Each antibody recognizes a specific antigen unique to its target. By binding their specific antigens, antibodies can cause agglutination and precipitation of antigen-antibody products, prime for phagocytosis by macrophages and other cells, block viral receptors, and stimulate other immune responses, such as the complement pathway.

\begin{tabular}{|c|c|c|c|c|}
\hline Name & Type & Complex & Primary Function & Special properties \\
\hline $\operatorname{Ig} \mathrm{A}$ & 2 & Dimer & $\begin{array}{l}\text { Prevents gut and airways } \\
\text { colonization by pathogens }\end{array}$ & \\
\hline $\operatorname{IgD}$ & 1 & Monomer & $\begin{array}{l}\text { Functions as an antigen receptor } \\
\text { on B-cells unexposed to antigens }\end{array}$ & \\
\hline $\operatorname{IgE}$ & 1 & Monomer & $\begin{array}{l}\text { Binds to allergens and triggers } \\
\text { histamine release }\end{array}$ & \\
\hline IgG & 4 & Monomer & $\begin{array}{l}\text { Provides the majority of antibody- } \\
\text { based immunity }\end{array}$ & $\begin{array}{l}\text { Can crossover from } \\
\text { placenta to provide } \\
\text { passive immunity }\end{array}$ \\
\hline $\operatorname{Ig} M$ & 1 & Pentamer & $\begin{array}{l}\text { Eliminates pathogens in the early } \\
\text { stages of B cell mediated IR }\end{array}$ & \\
\hline
\end{tabular}

Table 2. Antibody types and their functions

\section{Expression of Mu opioid receptor on immune cells}

\subsection{Opioid system and its components}

Opioids are chemicals that work by binding to opioid receptors, found in the central and peripheral nervous system and the gastrointestinal tract. Opioids play diverse biological functions, including reward, analgesia, and stress responsivity (Kreek and Koob, 1998; Vaccarino et al., 2000) and have been extensively studied for their therapeutic properties.

For opioids to be biologically active they must engage with any of the three principal classes of opioid receptors, namely, $\mu, \kappa, \delta$ (mu, kappa, and delta). In all about seventeen different receptor types are reported, which include the $\varepsilon, 1, \lambda$, and $\zeta$ (Epsilon, Iota, Lambda and Zeta) receptors. These receptors share the common feature of binding to opioids/opiates with high affinity and classical stereo-selectivity. Cloning of the opioid receptors allowed their classification into the super-family of seven trans-membrane domain guanine-protein (Gprotein) coupled receptors and are known to be involved in GABAnergic neurotransmission and their activation is reversed by the opioid inverse-agonist naloxone. The opioid receptors show a very high degree of sequence similarity at both nucleotide and protein levels. The homology is particularly striking in the seven trans-membrane domains and three intracellular loops. The extra-cellular N-terminal domain, three extra-cellular loops and the intra-cellular carboxy-terminal domains are less conserved among the three receptor types. Chromosomal locations for the human opioid receptors and opioid peptide genes have been established and are summarised in Table 3. 


\begin{tabular}{|l|l|l|}
\hline Protein & Gene & Location \\
\hline Mu opioid recptor & OPRM1 & $6 \mathrm{q} 24-25^{\mathrm{d}}$ \\
\hline Kappa opioid recptor & OPRK1 & $8 \mathrm{q} 11.2^{\mathrm{e}, \mathrm{g}}$ \\
\hline Delta opioid recptor & OPRD1 & $1 \mathrm{p} 34.3-36.1^{\mathrm{f}}$ \\
\hline Preproopiomelanocortin & POMC & $2 \mathrm{p} 23.3 \mathrm{a}, \mathrm{b}, \mathrm{h}$ \\
\hline Preproenkephalin & PENK & $8 \mathrm{q} 23-\mathrm{q}^{2} \mathrm{c}^{\mathrm{c}}$ \\
\hline Preprodynorphin & PDYN & $20 \mathrm{p} 12-$ pterc $^{\mathrm{c}}$ \\
\hline
\end{tabular}

Table 3. Chromosomal locations of human genes coding for opiate receptors \& endogenous opioid peptides

Endogenous opioid peptides and their receptors form a neuromodulatory system that impacts several physiological processes, such as cognition, pain control, emotions, response to stress, and pathophysiology of both addiction to and immunosuppressive effects of opiates (Olson et al., 1996). Despite a number of side effects, such as respiratory depression, constipation, tolerance and dependence, morphine remains one of the most valuable therapeutic drugs (Schug SA et al., 1992).

Clinicians have long known that apart from being addictive opiates also cause immunosuppression. Present knowledge of interaction between opiates and the immune system is based on pharmacological studies and several mechanisms have been proposed. In vitro experiments suggest that opiates act directly upon immune cells (Sibinga and Goldstein, 1988; Chuang et al., 1995). Some reports indicate detectable expression of $\mu$ opioid receptor (MOR) mRNA in immune cells suggesting that these cells are targets for direct opioid action (Smolka and Schmidt, 1999). Others have proposed the existence of non-classical receptors, which specifically bind $\beta$-endorphin or recognize alkaloids but not peptidic opioid ligands (Pasternak., 1993). Pharmacology of opiates on immune responses seems complex, due to presence of a wide diversity of opiate receptors and therefore the molecular basis of opiate action on the immune system needs to be further studied.

Allelic variants in the opioid receptor and/or opioid peptide genes may lead to an altered endogenous opioid system. More than 100 polymorphisms have been identified in the human OPRM1 gene and at least 10 single nucleotide polymorphisms (SNPs) have been reported in OPRM1-translated regions (Bond et al., 1998; Hoehe et al., 2000). Of these 10 SNPs, the A118G variant (rs 1799971) is the most prevalent and widely studied. The 118G allele is reported to increase the affinity of MOR for $\beta$-endorphin, an endogenous opiate, and activate inwardly rectifying potassium channels with three times greater potency than the most prevalent A118 allele (Bond et al., 1998). Although pharmacological studies suggest that the inhibitory action of opiates on immunity is mediated by opioid receptors, however molecular evidence for individual differences remains elusive.

\subsection{Opioid receptors and immune functions}

Opiates are immunosuppressive drugs and cause a decrease in several immune components (Brown et al., 1974). Jankovic and Maric (1987) showed that the neuropeptides, methionineenkephalin, leucine-enkephalin, especially the former, exhibit a protective action against 
anaphylactic shock in rats sensitized to ovalbumin. On the other hand small doses of enkephalins stimulated humoral immune responses in rats. Thus, it appears that enkephalins both suppress and potentiate immune responsiveness. Naloxone, a blocker of opioid receptors, enhanced humoral immune reactions in rats.

Sibinga and Goldstein (1988) first showed that opioid receptors are expressed on cells from the immune system as determined by receptor binding and functional assays. Opioid alkaloids and peptides, such as morphine and endogenous opioid peptides, namely $\beta$ endorphin, have been shown to modulate the function of lymphocytes and other cells involved in host defence and immunity. Results from several laboratories have indicated that opioids can operate as cytokines, the principal communicating signals among the immunocytes. Indeed, all of the major properties of cytokines are shared by opioids, i.e., production by immune cells with paracrine, autocrine, and endocrine sites of action, functional redundancy, pleiotropy, and effects that are both dose and time dependent (Peterson et al., 1998). The $\mu$-selective opioid, DAMGO, has been shown to increase the release of the monocyte chemoattractant protein-1 (MCP-1), RANTES, and interferon- $\gamma$ from human peripheral mononuclear cells. Buprenorphine, another compound, known to have both agonist and antagonist properties at the MOR, has been shown to suppress splenic NKcell activity, lymphocyte proliferation, and IFN- $\gamma$ production in rats in a naltrexonereversible manner suggesting a role of MOR in immune-modulations (Bidlack, 2006). Opiates like morphine, heroin, fentanyl and methadone are known to induce immunesuppression and affect both innate and adaptive immunity defining a role of MOR in these functions (Roy et al., 2006). Immune cells at different stages of differentiation express MOR differentially. Morphine affects the development, differentiation and function of various immune cells (Roy et al., 2006). Opiates directly bind to both classical and non-classical opioid receptors on immune cells and thus modulate their function. They also bind to classical opioid receptors in the CNS, causing the release of catecholamines and/or steroids, which in turn further affect the immune cell functions. They play a role in suppressing a variety of immunological end points such as proliferation, functions and responses of both $\mathrm{T}$ and B cells and attenuating the cytokine system (Vallejo et al., 2004;). They also suppress movement and number of circulating white blood cells (Miyagi et al., 2000; Perez-Castrillon et al., 1992).

\section{Clinical observations}

\subsection{In opiate dependent subjects}

Heroin addicts have been repeatedly documented to have an increased susceptibility to a variety of infectious diseases, and also depict alterations in a wide variety of immune cell parameters. These subjects manifest a variety of changes in the immune system indicative of both decreased and increased immune responses. While the absolute number and percentage of total and active T lymphocytes in the peripheral blood of opiate addicts and Tcell rosette formation were found to be significantly depressed in one study, an increase in the absolute number of T-cells in the blood of heroin addicts was reported in another. Similar conflicting results have been reported concerning the functional activity of $\mathrm{T}$ lymphocytes from heroin addicts. Brown et al. (1974) found impaired responsiveness, in vitro, of lymphocytes to each of the three mitogens (PHA, concavanalin A, pokeweed mitogen) in heroin addicts relative to control values but another group reported normal $\mathrm{T}$ proliferative responses to both concavanalin A and tetanus toxoid antigen in another group 
of healthy addicts. Immunophenotypic markers on lymphoid cells in human addicts have been studied using flow-cytometric analysis and a profound decrease in the Thelper/cytotoxic T- cell (CD4/CD8) ratio in heroin addicts as well as a normal pattern of Tcell subsets and a normal CD4/CD8 ratio in another group of healthy intravenous drug abusers and methadone patients has been reported by separate groups. More, recent studies have further established the immunosuppressive effects of opioids. Morphine has been shown to antagonize IL- $1 \alpha$ and TNF- $\alpha$ induced chemotaxis in human leucocytes as well decrease levels of IL-2 and IFN- $\gamma$ and increase levels of IL-4 and IL-5. They have also been shown to suppress expression of antigenic markers on T- helper cells.

Opiate use is known to depress E-rossette formation, indicating clinical immunosuppression. Long-term use of opiates produces atrophy of lymphoid organs, decreases lymphoid content, alters antigen-specific antibody production, causes loss of $\mathrm{T}$ helper (Th) cells (McDonough et al., 1980; Donahoe et al., 1987) and decreases T cell reactivity, T helper/T cytotoxic cell ratios and T helper cell function specifically (Thomas et al., 1995; Rouveix, 1992). Opiates are known to impair both immunoglobulin synthesis, function and induce immunonutritional deficiencies (Varela et al., 1997). Humoral immunity can be assessed by determining the levels of immunoglobulins, which are antigenic receptors, secreted by Bcells. Alterations of normal immunoglobulin concentration in opiate users are an indication of immunologic impairment (Rho 1972). Alterations in immunoglobulin (Ig) synthesis, concentration and function (Thomas et al., 1995; Islam et al., 2004) are indication of immunologic impairment in opiate users (Rho, 1972; Islam et al., 2001; 2002).

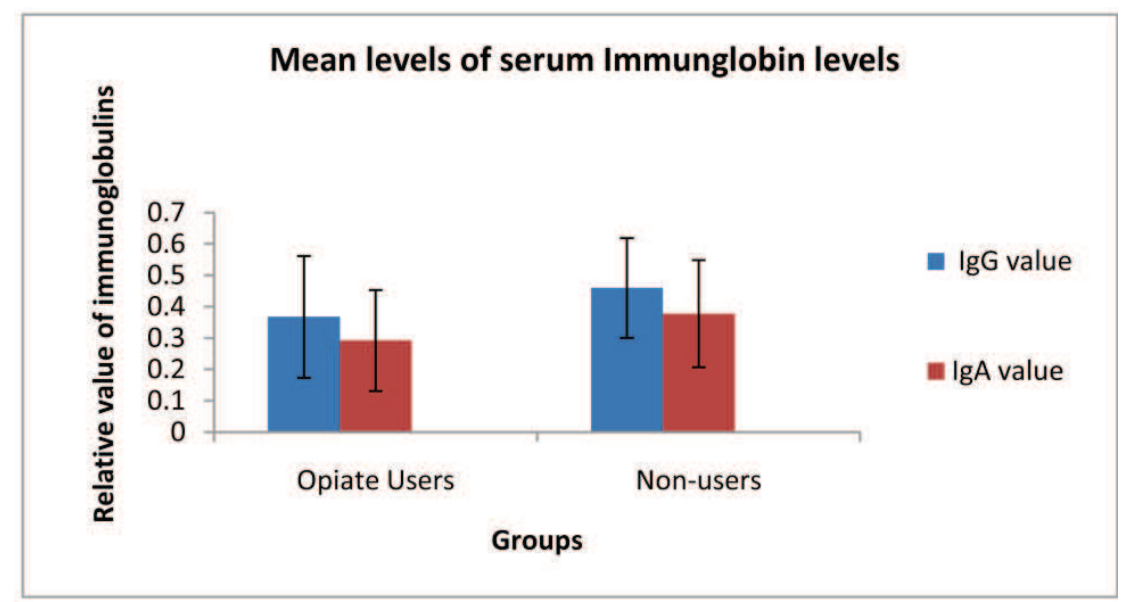

Fig. 1. Serum IgG, IgA levels in Opiate users \& Nonusers

A decrease of IgA levels and increase of IgG and IgM levels has also been reported in Indian opiate users as compared to non-users (Naik et al., 2001; Islam et al., 2004). We used a genetic approach to correlate a functional OPRM1 gene polymorphism with known action of opiates on immunity and a prospective study was undertaken to address the relationship of the A118G variation with the amount of exogenous opiates consumed and correlate the immunosuppressive effects of exogenous opiates with the MOR alleletype among opiatedependent and control subjects from northern India. We investigated the immune status of opiate users by measuring serum Ig (IgG and IgA) levels, in association with specific MOR 
genotype of the study subjects (Sharad et al., 2007). Our findings confirmed that the mean circulating levels of Ig were significantly lower in opiate users when compared with levels in cohort controls (Figure 1). Among opiate dependent subjects, individuals with AA genotypetype were found to have the lowest levels of circulating Igs, both IgG and IgA $(p=0.0001)$ while the AG genotype carrying individuals had a higher level of both Igs. The homozygous GG genotype was in between the AA and AG genotypes (Figure 2).

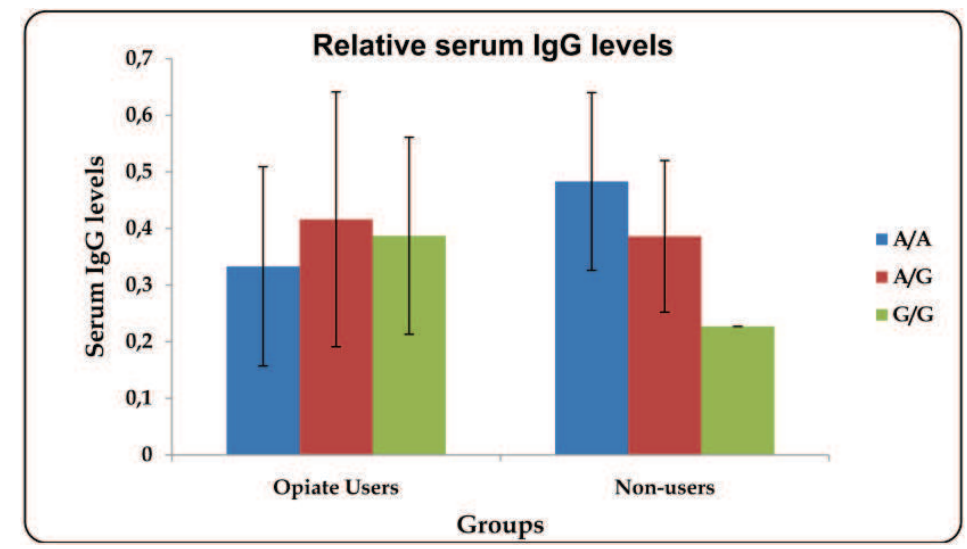

Fig. 2. Serum IgG Values in Opiate users and Non-users with different MOR genotypes

\subsection{Auto-antibodies in individuals with different MOR alleles}

Autoantibodies (aAbs) is a greek derived word meaning against the self as "auto" means "self", "anti" means "against" and "body". They are produced by the immune system but recognise the proteins produced in the individual's own body. The antibodies that usually attack the proteins present in the nucleus of the cell are called antinuclear antibodies (ANA). It is a known that about $15 \%$ of the completely normal population tests positive for ANA.

The interactions between these receptors and immune system, including autoimmune responses, are poorly understood. Granstrem and his co-workers (2006) showed that administration of morphine significantly elevate the levels of aAbs to mu delta-opiate receptor (MDOR). At the same time psycho-stimulant drug, d-amphetamine, or a commonly abused substance, nicotine, had no effect on these aAbs levels. Such observations support the hypothesis that, opiates could be common mediators between the nervous and the immune system. The high levels of aAbs to MDOR were also observed in heroin selfadministering rats as well as in human addicts and shown as a function of severity of opiate addiction (Dambinova and Izykenova, 2002), suggesting that opiate addiction may be somehow associated with autoimmune response/processes.

Koziol and collègues (1997) compared the range of ANA in "healthy" individuals in comparison with patients with autoimmune disorders such as systemic lupus erythematosus, systemic sclerosis, sjogren's syndrome and rheumatoid arthritis, or soft tissue rheumatism. Their findings revealed that in healthy individuals, the frequency of ANA did not differ significantly across the 4 age subgroups spanning 20-60 years of age. This putatively normal population was ANA positive in $31.7 \%$ of individuals at $1: 40$ serum dilution, $13.3 \%$ at $1: 80,5.0 \%$ at $1: 160$, and $3.3 \%$ at $1: 320$ (Koziol, 1997). Experiments by Bendtzen and co-workers (1993) confirmed the presence of nano-to-picomolar concentrations 
of high affinity IgG antibody to interleukin 6 (IL-6ab) in sera of 15\% normal Danish blood donors. The same group had earlier shown presence of detectable autoantibodies against IL$1 a$ in sera from $10 \%$ of normal human subjects (Bendtzen, et al., 1989).

To study the functional consequences of OPRM1 genotype as early modifiers of autoimmune response we estimated ANA in opiate dependent subjects with A118 or G118 MOR allele (unpublished data; Kapur S and co-workers). A sandwich ELISA assay was performed using Nuclear S100 extract prepared from lymphocytes of normal individuals. The whole complement of the nuclear fraction was used to increase the antigen repertoire. In order to test the impact of OPRM1 genotype, plasma from diagnosed cases of Rheumatoid Arthritis, clinically known to have a higher level of circulating ANA, were also tested for comparison. True to our projections our findings confirmed significantly higher titres of ANA in the rheumatoid arthritis subjects in comparison to those seen in plasma of opiate dependent and control subjects. The mean titres of ANA in the different groups are shown in Figure 3. The mean anti ANA titres in AA genotype bearing subjects were higher than those observed in GG genotype bearing subjects in all three groups studied.

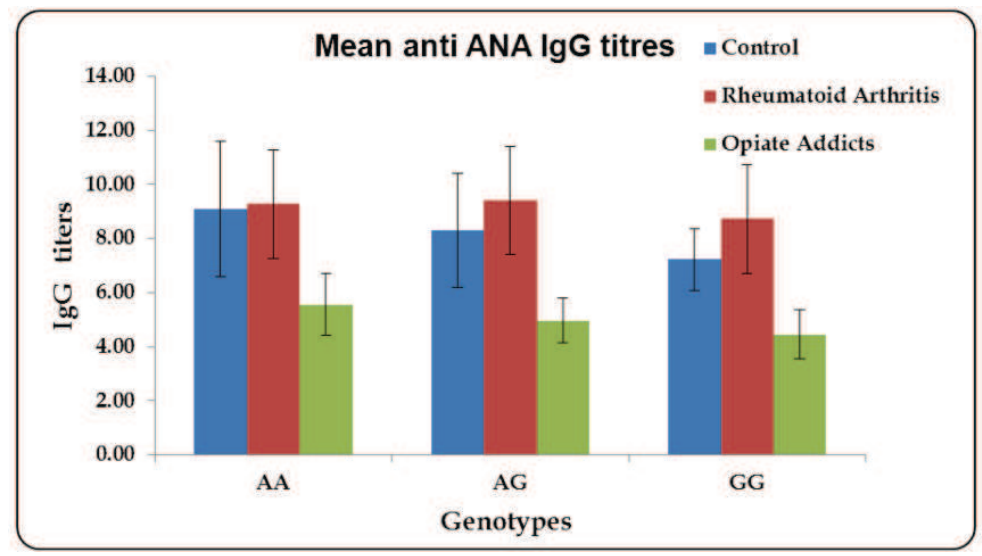

Fig. 3. Bar graph showing relative levels of ANA titres in the groups under study

\subsection{Chemokines in relation to MOR genotype}

Chemokines consist of a family of 8-16 kDa cytokines that are generated very early in a wide variety of inflammatory responses and attract leukocytes to local sites. At nanomolar concentration chemokines initiate signal transduction and activate leukocytes through seven transmembrane (STM) receptors, but higher micromolar doses result in homologous desensitizing effects. Chemokines along with adhesion molecules orchestrate the migration of opioid peptide-containing leukocytes to inflamed tissue. Leukocytes secrete opioid peptides under stressful conditions or in response to releasing agents such as corticotropinreleasing factor and other chemokines. Due to the crucial role of chemokines in recruitment of leukocytes to sites of inflammation they play a vital role in a variety of infective/antiinflammatory diseases. Chemokines are subdivided according to their structure into two subgroups, of which the largest are the CXC, or alpha, and CC, or beta groups defined by the presence or absence of an additional amino acid (" $X$ ") respectively between the first two cysteine residues in a conserved four cysteine motif. The alpha chemokines are further subdivided according to the presence or absence of a glutamine-leucine-arginine (ELR) amino- 
acid sequence near the active site. Those possessing this sequence are potent chemoattractants for neutrophils while those that do not possess the motif are chemotactic for lymphocytes.

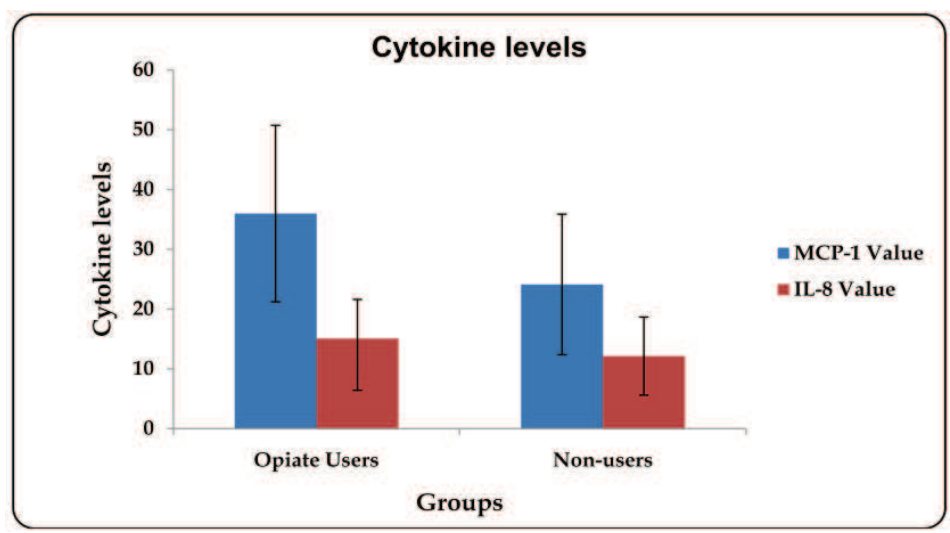

Fig. 4. Mean levels of cytokines (MCP-1and IL-8 values (pg/ml)) in Opiate users and Non-users

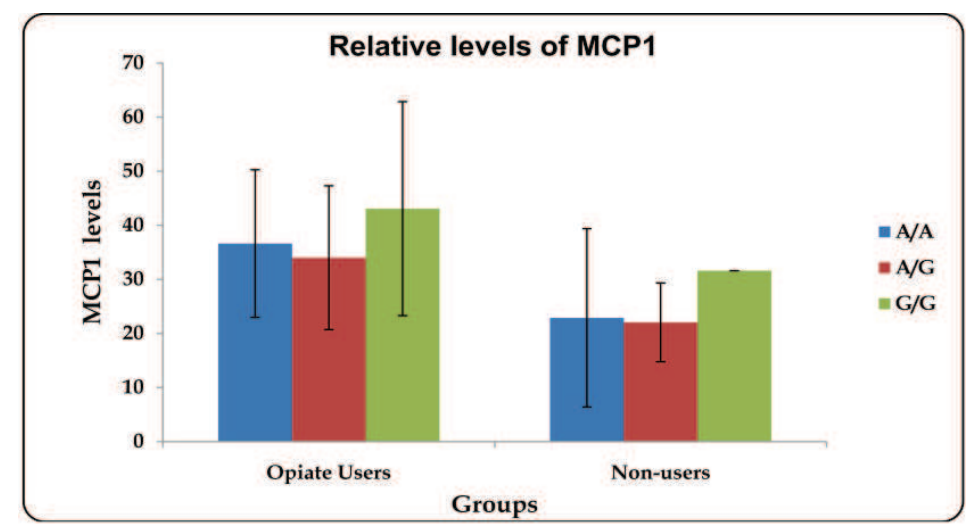

Fig. 5. MCP-1 Values $(\mathrm{pg} / \mathrm{ml})$ in Opiate users and Non-users with different MOR genotypes

Interleukin 8 (IL-8) possesses an ELR amino acid-sequence and is the prototype alpha chemokine, being exclusively chemotactic for neutrophils. IL-8 is produced by macrophages and other cell types such as epithelial cells and is also synthesized by endothelial cells, which store IL-8 as storage vesicles. IL-8 has potent chemotactic activity at nanomolar and picomolar concentrations for neutrophils and lymphocytes, respectively (Larsen et al., 1989) and induces leukocyte trans-endothelial transmigration (Zoja et al., 2002). Thus, IL-8 is better known for its role in inflammatory diseases, where it attracts white blood cells into an area of tissue injury and sites of inflammation. On the basis of reports that opiates have antiinflammatory effects and also use STM, it has been postulated that they may crossdesensitize the response of leukocytes to chemokines. Met-enkephalin (MET) is chemotactic for human peripheral blood monocytes. Indeed it has been observed that preincubation of monocytes or neutrophils with MET or morphine prevented their subsequent chemotactic response to chemokines (MIP1 or IL-8). However, MET does not inhibit the chemotactic 
response of PMN to NAP-2, a homologous chemokine that is less potent than IL-8 but cannot be desensitized. The inhibitory effect of opiates on chemokine-induced chemotaxis was also antagonized by naloxone. Since MIP-1 and IL-8, unlike NAP-2, have the capacity to desensitize leukocytes, it is reasonable to expect that opiates, by desensitizing some chemokine responses, can suppress inflammatory reactions.

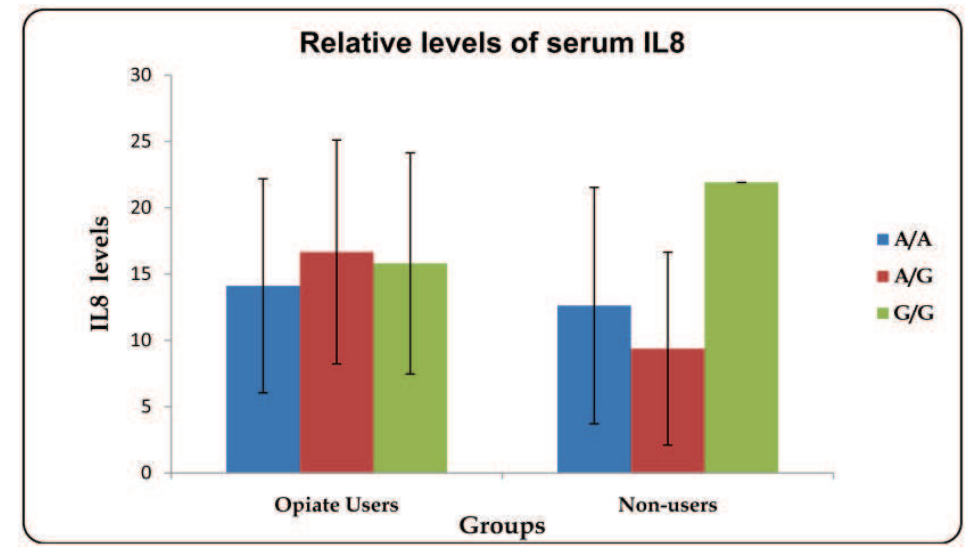

Fig. 6. IL-8 Values (pg/ml) in Opiate users and Non-users with different MOR genotypes

$\mathrm{Mu}$ opioids have been shown to alter the release of chemokines important for both host defence and inflammatory response. Exposure to morphine has been shown to suppress production of IFN-a, IL-2 and IL-4 by lymphocytes (Lysle et al., 1993; Geber et al., 1975; Bhargava et al., 1994). Wetzel et al., (2000) showed that mu selective agonists increased the expression of the CC chemokine, MCP-1. MCP-1 plays a major role in two distinctly different host responses: cellular immune reactions and responses to active tissue injury (Leonard et al., 1990). MCP-1 can be produced by leukocytes of both lymphocyte and monocyte lineages and is specific for monocytes, macrophages and activated T cells. MCP-1 can both initiate and amplify monocyte recruitment to the microvascular walls, and let monocyte enter into the tissues and be transformed into macrophages (Sozzani et al., 1995). Recruitment of macrophages into tissues is an important process in inflammation and host defence and thus both MCP-1 and IL- 8 both play a significant role in inflammation and host defence. Mean MCP-1 levels in dependent subjects were $35.87 \mathrm{pg} / \mathrm{ml}$ (ranging between 8.95$80.81 \mathrm{pg} / \mathrm{ml})$ while in non-users it was $24.12 \mathrm{pg} / \mathrm{ml}(5.87-109.1)$ and were significantly higher in opiate users as compared to control subjects $(\mathrm{p}=0.0001, \mathrm{t}=6.398)$. The mean IL-8 in opiate dependent subjects was $15.08 \mathrm{pg} / \mathrm{ml}$ (ranging between 1.580-44.38) and 12.13 $\mathrm{pg} / \mathrm{ml}$ (ranged from 3.390-37.60) in control subjects (non users). The levels in addicts were significantly higher in comparison to control subjects $(p=0.0061, t=2.773)$ as shown in Figures 4-6. The presence of $118 \mathrm{G}$ allele was found to be associated with increased levels of both MCP1 and IL- 8 and can be envisaged to play a critical role in chemotactic migration of both lymphocytes and neutrophils to site of inflammation and tissue injury.

\section{Observations in cases of therapeutic use of opiates as analgesics}

One of the most frequent conditions for which morphine is used is the treatment of pain. Hashiguchi and colleagues (Hashiguchi et al., 2005) published a study with a limited 
number of patients who were receiving morphine therapy for advanced cancer pain. Although not conclusive, this work suggests that both humoral and cellular immunity are modulated by morphine and its metabolites during the early phases of therapy, and that such immune-modulation can have long-term detrimental effects.

The immunosuppressive properties of another potent opioid fentanyl have been shown to affect cellular immune responses in humans in a dose related manner (Jacobs et al., 1999 \& Beilin et al., 1996). In another study, patients with a long history of heroin intake when switched to high doses of buprenorphine showed significant immuno-suppression. Endogenous opiates lead to elevated plasma levels of corticotrophin releasing hormone, adrenocorticoid hormone and glucocorticoids, which further lead to immune suppression and increased incidence of opportunistic infections. Inhibitory action of morphine on immune responses, demonstrated both in animal models and humans (Quaglio et al., 2002; Nath et al., 2002) accounts for increased susceptibility to opportunistic infections in opiate dependent subjects (Vallejo et al., 2004).

MOR is expressed in ileal and colonic enteric neurons as well as in immunocytes such as myeloid cells and CD4+ and CD8+ T cells. Specific host defense in the intestine is mediated by the gut-associated lymphoid tissue (GALT), which comprises the largest mass of immune cells in the body. GALT, which consists of both organized and diffuse lymphoid tissue mediates immune protection at both local and distant anatomical sites through local dimeric IgA secretion and the ability of lymphocytes activated at one mucosal site to recirculate and home to other mucosal surfaces (Mowat \& Viney, 1997). Thus, humoral immunity in GALT is conveyed by plasma cells committed to IgA synthesis and IgA-producing plasma cells circulate throughout the lymphatic system and protect other mucosal surfaces (Croitoru \& Bienenstock., 1994). Polymeric IgA is transported into epithelial cells via secretary component and released into the lumen as secretary $\operatorname{IgA}(\operatorname{sIg} \mathrm{A})$ where it can neutralize viruses and prevent bacterial adherence to the activated mucosa.

\section{Epigenetics and OPRM1 gene}

Genetic studies have revealed the existence of several common susceptibility genes for autoimmune/inflammatory disorders. However, genetic variation represents only half of the story. Recent studies have unequivocally established that epigenetic mechanisms regulate gene expression and are sensitive to external stimuli, bridging the gap between environmental and genetic factors. Thus, gene function depends not only on DNA sequence, but also on epigenetic modifications, including both DNA methylation and histone posttranslational modifications. These modifications are influenced by environmental factors and are known to contribute to the pathogenesis of several autoimmune diseases. Several studies have highlighted the importance of the tissue-specificity of DNA methylation changes. Over and above the expression of basic genetic variability, the contribution of genetic factors to disease risk can be modulated by the environment. A number of internal and external environmental factors have been associated with the etiopathology of inflammatory disorders, including viral infection, nutrition, and exposure to chemicals and radiation. Such factors influence or modify the profile of epigenetic modifications, which, in turn, have a direct relationship with the regulation of gene expression, and ultimately the function of the immune system. Active demethylation has been described, particularly in cell (de)differentiation and reprogramming processes, and in the context of the activation of immune cells (Bhutani et al., 2010; Bruniquel \& Schwartz., 2003). The first suggestions of a potential role for DNA methylation in autoimmune disease came from studies in which 
small compounds that result in decreased DNA methylation, such as 5-azacytidine, hydralazine or procainamide, induced symptoms that are associated with autoimmune disease. For example, these drugs induce autoreactivity in CD4+ T cells, or antinuclear factors in both human and mouse models (Cannat \& Seligmann, 1968; Richardson, 1986; Cornacchia et al. , 1988). Most of the genes for which DNA hypomethylation has been reported are from the cluster of differentiation (CD) group, including ITGAL (also known as CD11A), (Lu et al., 2002) which is important for cell-cell adhesion, CD70 (encoding CD70, also known as tumor necrosis factor ligand superfamily member 7), (Oelke et al., 2004) which is required for T cell proliferation, clonal expansion and the promotion of effector $\mathrm{T}$ cell formation, and CD40LG (encoding CD40 ligand), (Lu et al., 2007) which stimulates B cell IgG overproduction.

On the other hand in case of hypermethylation of promoter sequences, transcription factorbinding sites have reduced binding affinity for their cognate transcription factors. Nielson et al (2009) examined whether there are differences in cytosine: guanine ( $\mathrm{CpG}$ ) dinucleotide methylation in the OPRM1 promoter between former heroin dependent subjects and controls. Analysis of methylation at $16 \mathrm{CpG}$ dinucleotides in DNA obtained from lymphocytes of 194 Caucasian former severe heroin addicts stabilized in methadone maintenance treatment and 135 Caucasian control subjects revealed significant methylation differences at the $-18 \mathrm{CpG}$ and $+84 \mathrm{CpG}$ dinucleotide sites in the propmoter region of the OPRM1 gene. Both the -18 and the $+84 \mathrm{CpG}$ sites are located in potential Sp1 transcription factor-binding sites. Methylation of these $\mathrm{CpG}$ sites may lead to reduced OPRM1 expression in the lymphocytes of these former heroin addicts and in turn impact the immune response mounted to both auto and external antigens.

\section{Failing to protect: Immune dysfunction spells trouble}

Immune suppression has been seen in patients suffering from heroin dependence (Naik et al., 2001). Opiate drug and its psychonutritional consequences have been reported to suppress movement and number of white blood cells (Perez-Castrillon et al., 1992; Herbert and Cohen, 1993; Scrimshaw and SanGiovanni 1997; Miyagi et al 2000). Opioid abuse is directly associated with some severe intestinal complications, including toxic megacolon, necrotizing enterides and necrotizing angiitis (Roszler et al., 1991). In addition, Gramnegative enteric bacteria have been implicated as causative agents in enterococcal endocarditis and other severe infections associated with opiate abuse. Recent studies with MOR deficient mice support a physiological anti-inflammatory effect of MOR at the colon interface (Philippe et al., 2006). Exogenous morphine reduces $\operatorname{IgA}$ production in the intestinal tract of mice in response to oral administration of cholera toxin (Dinari et al., 1989). Our own findings show that subjects with the prototypical A118A (AA) genotype are at a greater risk for active immuno-suppression by exogenous opiates. The marked reduction in circulating IgA observed in the AA genotype bearing dependent subjects suggests that such individuals could be at a higher risk for developing opiate-induced intestinal complications and/or defects in mucosal defence. This study also provides an insight into the probable molecular basis for differential adverse reactions, specifically gastrointestinal complications in different individuals. However, more studies are required to further elucidate whether MOR genotype differences contribute to an individual's vulnerability to develop gastrointestinal disorders linked with opiate addictions and / or the course and outcome of inflammatory/infectious diseases due to active immuno-suppression by exogenous opiates. This review also provides an insight into the probable molecular basis 
for differential adverse immune reactions and gastrointestinal complications in different individuals.

\section{Conclusion}

Opioid receptors are expressed in cells of the immune system, and potent immunomodulatory effects of their natural and synthetic ligands have been reported. Opiate drugs are known to possess direct suppressive effects on cellular and humoral immunity by influencing both the function of immunocompetent cells and inflammation mediator gene/s expression and secretion (Shin and Masato, 2008). In turn, the major source of local endogenous opioid ligands (beta-endorphin, enkephalins, endomorphins and dynorphin) are leukocytes themselves. Both in vivo and in vitro opioids affect activity of leukocytes and expression of inflammatory molecules, such as chemokines and chemokine receptors, in leukocytes. Chemokines induce cellular migration and are crucial players in initiating both innate and adaptive immune response (Figure 7).

A series of very early inflammatory events induce activation of tissue and endothelial cells and culminates in production of chemokines such as interleukin-8 (IL-8) that induce migration of neutrophils to the affected site where they inactivate pathogens by phagocytosis or release of microbicides (Shen et al., 2006). U87 (astrocytoma), normal human astrocyte (NHAs) (Neudeck and Loeb, 2002) and Caco2 (Neudeck et al., 2003) cells treated with morphine showed significant down-regulation of proinflammatory chemokines such as IL-8, MCP-1, and MIP-1 beta and this was inhibited by treatment with MOR antagonist, beta-funaltrexamine (Mahajan et al., 2005).

Opioid receptors activate several intracellular pathways, such as closing of voltage-sensitive calcium channels, opening of potassium channels leading to cellular hyper-polarization and decrease in cyclic AMP production through inhibition of adenylate cyclase. Predominant channels found in lymphocytes are voltage-gated $\mathrm{K}+$ channels and several lines of evidence suggest that these channels are involved in lymphocyte function/s. Vassou et al (2008) have suggested that the effects of opioids on B-lymphocytes may be attributed to interplay between distinct cell populations. Findings from our lab show that the presence 118G allele not only impacts the amount of drug consumed, but also influences the immunomodulation caused by exogenous opiates. The individuals homozygous for AA genotype seem to be more vulnerable to suppression of humoral immunity (antibody production by B cells) while those with GG genotype could be protected against such depression of B-cell function. Indeed, Vassou et al. (2008) have shown that opiates like morphine, alphas1-casomorphin and ethylketocyclazocine modulate antibody and cytokine secretion by multiple myeloma cells in a cell line-dependent manner and decrease antibody secretion by normal B-lymphocytes. Data from both transfected cells and human autopsy brain tissue from carriers of 118G allele indicate that this allele may produce deleterious effect on mRNA and corresponding MOR protein yield (Janicki et al., 2006). Based on the literature reviewed here it can be conclusively said that the complete repertoire of molecular consequence of the 118G SNP on receptor function in various immune cells and nevous tissue still remain unelucidated. A larger study to delineate the effect of AG and GG alleles on suppression of B cell function in the carriers, increasing susceptibility to consequent metabolic compromises leading to diseases and to establish the utility of of this SNP as a marker for estimating adverse immune-modulation in opiate dependent subjects and patients under treatment with opiate drugs needs to be undertaken in different ethnic populations world wide. 


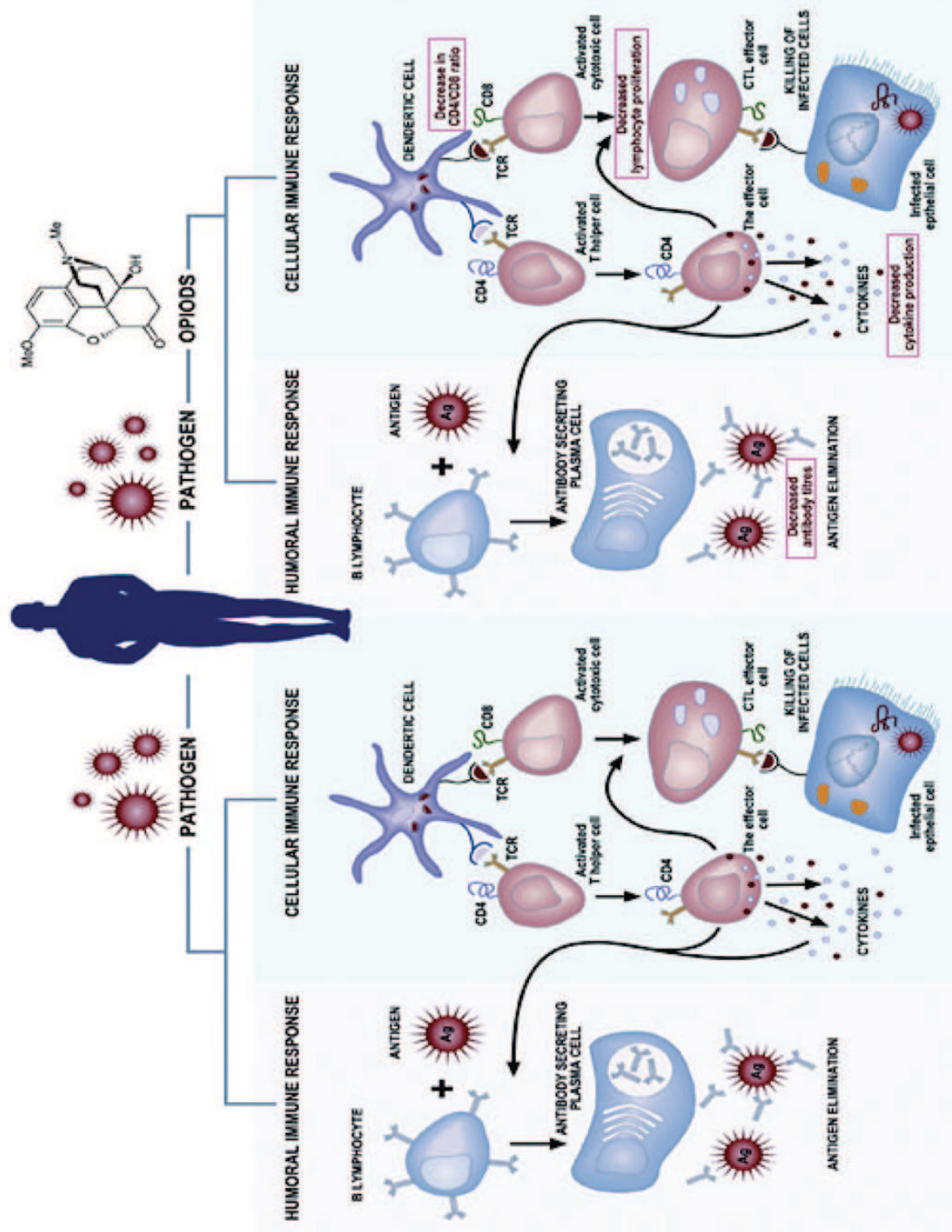

Fig. 7. Effect of opioid intake on immune system

\section{Acknowledgment}

This work was supported by an extramural grant to Dr Suman Kapur and fellowship to Dr. Shashwat Sharad from Indian Council Medical Research, New Delhi, and to Council of Scientific and Industrial Research, New Delhi for fellowship awarded to Ms. Anuradha Pal. 


\section{References}

Befort, K., et al. (1994). Chromosomal localization of the delta opioid receptor gene to human 1p:14.3-p36.1 and mouse 4D bands by in sim hybridization. Genomics 20:143-145.

Beilin, B., et al. (1996). Effects of anesthesia based on large versus small doses of fentanyl on natural killer cell cytotoxicity in the perioperative period. Anesth Analg. 82:492-497.

Bendtzen K., et al. (1989). IgG Autoantibodies against Interleukin 1a in Sera of Normal Individuals. Scandinavian Journal of Immunology. 29(4):489-492.

Bendtzen K., et al. (1993). High-affinity IgG autoantibodies to IL-6 in sera of normal individuals are competitive inhibitors of IL-6 in vitro. Cytokine. 5(1):72-80.

Bhargava, H.N., et al. (1994). Effects of morphine tolerance and abstinence on cellular immune function. Brain Res. 642:1- 10.

Bhutani, N., et al.(2010). Reprogramming towards pluripotency requires AID-dependent DNA demethylation. Nature. 463:1042-1047.

Bidlack, J.M., et al. (2006). Opioid Receptors and Signaling on Cells from the Immune System. Journal of Neuroimmune Pharmacology. 1(3):260-269.

Bond, C., et al. (1998). Single-nucleotide polymorphism in the human mu opioid receptor gene alters beta-endorphin binding and activity: possible implications for opiate addiction. Proc Natl Acad Sci USA. 95:9608-9613.

Brown, S.M., et al. (1974). Immunologic dysfunction in heroin addicts. Arch Intern Med. 134(6):1-6.

Bruniquel, D., \& Schwartz, R.H. (2003). Selective, stable demethylation of the interleukin-2 gene enhances transcription by an active process. Nat. Immunol. 4:235-240.

Cannat, A., \& Seligmann, M. (1968). Induction by isoniazid and hydralazine of antinuclear factors in mice. Clin. Exp. Immunol. 3:99-105.

Cantacuzene, J. (1898). Nouvelles recherches sur le monde de destruction des vibrions dans l'organisme. Ann Inst Pasteur. 12:273-300.

Chuang, T.K., et al. (1995). Mu Opioid Receptor Gene Expression in Immune Cells. Biochem Biophys Res Commun. 216:922-930.

Cornacchia, E., et al. (1988). Hydralazine and procainamide inhibit T cell DNA methylation and induce autoreactivity. J. Immunol. 140:2197-2200.

Croitoru, K. \& Bienenstock, J. (1994). Characteristics and functions of mucosa-associated lymphoid tissue. In Add edition. Handbook of Mucosal Immunology (ed. Ogra, P. L. et al). 141-149, San Diego: Academic Press.

Dambinova, S.A. \& Izykenova, G.A. (2002). Recombinant mu-delta receptor as a marker of opiate abuse. Ann. N. Y. Acad. Sci. 965:497-514.

Dinari, G., et al. (1989). The effect of opiates on the intestinal immune response to cholera toxin in mice. Digestion. 44:14-19.

Donahoe, R. M., et al. (1987). Mechanistic Implications of the Findings That Opiates and Other Drugs of Abuse Moderate T-Cell Surface Receptors and Antigenic Markers. Am NY Acad Sci. 496:711-721.

Geber, W.F., Lefkowitz, S.S. \&. Hung, C.Y. (1975). Effect of morphine, hydromorphone, methadone, mescaline, trypanblue, vitaminA, sodiumsalicylate, and caffeine on the serum interferon level in response to viral infection. Arch. Int. Pharmacodyn. 214:322- 327.

Georges, H., Leroy, O., Vandenbussche, C., Guery, B., Alfandari, S., Tronchon, L., Beaucaire, G. (1999). Epidemiological features and prognosis of severe community-acquired pneumococcal pneumonia. Intensive Care Med. 25 (2): 198- 206. 
Hashiguchi, S., et al. (2005). Effects of morphine and its metabolites on immune function in advanced cancer patients. J Clin Anesth. 17:575-580.

Herbert, T.B. \& Cohen, S. (1993). Stress and immunity in humans: a meta-analytic review. Psychosom Med. 55(4):364-79.

Hoehe, M.R., et al. (2000). Sequence variability and candidate gene analysis in complex disease: association of $\mathrm{mu}$ opioid receptor gene variation with substance dependence. Hum Mol Genet. 9:2895-2908.

Islam, S. N. et al. (2002). Nutritional Status of the Drug Addicts undergoing detoxification: prevalence of malnutrition and influence of illicit drugs and life style. Br J Nutr. 88:507-513.

Islam, S. N., Hossain, K. J. \& Ahsan, M. (2001). Original Communication: Serum vitamin E, $\mathrm{C}$ and $\mathrm{A}$ status of the drug addicts undergoing detoxification: influence of drug habit, sexual practice and lifestyle factors. Eur J Clin Nutr. 55:1022-1027.

Islam, S.K., et al. (2004). Serum immunoglobulins and white blood cells status of drug addicts: influence of illicit drugs and sex habit. Addict Biol. 9(1):27-33.

Jacobs, R., et al. (1999). Effects of fentanyl on cellular immune in man. Int J Immunopharmacol. 21: 45-454.

Janicki, P.K., et al. (2006). A genetic association study of the functional A118G polymorphism of the human mu-opioid receptor gene in patients with acute and chronic pain. Anesth Analg. 103(4):1011-7.

Janković, B.D. \& Marić, D. (1987). Enkephalins and immunity. I: In vivo suppression and potentiation of humoral immune response. Ann N Y Acad Sci. 496:115-25.

Koziol, J.A., et al. (1997). Range of antinuclear antibodies in "healthy" individuals. Arthritis Rheum. 40(9):1601-11.

Kreek, M.J. \& Koob, G.F. (1998). Drug dependence: stress and dys-regulation of brain reward pathways. Drug Alcohol Depend. 51: 23-47.

Larsen, C.G., et al. (1989). The neutrophil-activating protein (NAP-1) is also chemotactic for T lymphocytes. Science. 243:1464-1466.

Leonard, W.J., Gnarra, J.R. \& Sharon, M. (1990). The multisubunit interleukin-2 receptor. Ann N Y Acad Sci . 594:200-206.

Litman G.W., Cannon J.P. \& Dishaw L.J. (2005). Reconstructing immune phylogeny: new perspectives. Nature Reviews. Immunology. 5(11):866-79.

Litt, M., et al. (1988). Chromosomal localization of the human proenkephalin and prodynorphin genes. Am J Hum Genet. 42(2): 327-334.

Lu, Q., et al. (2002). Demethylation of ITGAL (CD11a) regulatory sequences in systemic lupus erythematosus. Arthritis Rheum. 46:1282-1291.

$\mathrm{Lu}, \mathrm{Q}$, et al. (2007). Demethylation of CD40LG on the inactive X in T cells from women with lupus. J. Immunol. 179:6352-6358.

Lysle, D.T., et al. (1993). Morphine induced alterations of immune status: dose dependency, compartment specificity and antagonism by naltrexone. J.Pharmacol.Exp.Ther 265 (3):1071- 1078.

Mahajan, S.D., et al. (2005). Morphine modulates chemokine gene regulation in normal human astrocytes. Clin Immunol . 115(3):323-32.

Mayer, G. (2006). Innate (non-specific) Immunity. In: Immunology. Microbiology and Immunology On-Line Textbook. USC School of Medicine. 
McDonough, R.J., et al. (1980). Alteration of $\mathrm{T}$ and null lymphocyte frequencies in the peripheral blood of human opiate addicts: in vivo evidence for opiate receptor sites on T lymphocytes. J Immunol. 125 (6):2539-2543.

Miyagi, A.U., et al. (2000). Opioids suppress chemokine-mediated migration of monkey neutrophils and monocytes - an instant response. Immunopharmacology. 47:53-62.

Mowat, A.M. \& Viney, J.L. (1997). The anatomical basis of intestinal immunity. Immunol Rev. 156: $145-166$.

Naik, S., Vaswani, M., \& Desai, N.G. (2001). Humoral immune function in non-parenteral heroin dependence: Indian data. Alcoholism. 37(1):25-34.

Nath, A., et al. (2002). Molecular basis for interactions of HIV and drugs of abuse. J Acquir Immune Defic Syndr. 31(Suppl 2): S62-69.

Neudeck, B.L. \& Loeb. J.M. (2002). Endomorphin-1 alters interleukin-8 secretion in Caco-2 cells via a receptor mediated process. Immunol Lett. 84(3): 217-21.

Neudeck, B.L., Loeb, J., Buck, J. (2003). Activation of the K-opioid receptor in Caco-2 cells decreases interleukin-8 secretion. Eur J Pharmacol. 467(1-3): 81-84.

Oelke, K., et al. (2004). Overexpression of CD70 and overstimulation of IgG synthesis by lupus T cells and T cells treated with DNA methylation inhibitors. Arthritis Rheum. 50:1850-1860.

Olson, G.A., Olson, R.D. \& Kastin, A.J. (1996). Endogenous opiates. Peptide. 17:1421-1466.

Owerbach, D., et al. (1981). The proopiocortin (adrenocorticotropin/beta-lipoprotein) gene is located on chromosome 2 in humans. Somatic Cell Genet. 7(3):359-69.

Pasternak, G.W. (1993). Pharmacological mechanisms of opioid analgesics. Clin Neuropharmacol. 1:1-18.

Perez-Castrillon, J. L., et al. (1992). Opioids depress in vitro human monocyte chemotaxis. Immunopharmacology. 23(1):57-61.

Peterson, P.K., Molitor, T.W. \& Chao, C.C. (1998). The opioid-cytokine connection. J. Neuroimmunol. 83:63-69.

Philippe, D., et al. (2006). Mu opioid receptor expression is increased in inflammatory bowel diseases: implications for homeostatic intestinal inflammation. Gut. 55(6): 815-823.

Pier, G.B., Lyczak, J.B., \& Wetzler, L.M. (2004). Immunology, Infection, and Immunity. ASM Press. ISBN 1-55581-246-5.

Quaglio, G., et al. (2002). Prevalence of tuberculosis infection and comparison of multiplepuncture liquid tuberculin test and Mantoux test among drug users. Scand J Infect Dis. 34(8):574-576.

Rho, Y.M. (1972). Infections as fatal complications of narcotism. NY St J Med. 72(7):823-830.

Roszler, M. H., McCarroll, K. A. \& Jacobs, I. J. (1991) Radiologic study of intravenous drug abuse complications, in Infections in Intravenous Drug Abusers, Oxford Univ. Press. New York. pp 96-151

Rouveix, B. (1992). Opiates and immune function. Consequences on infectious diseases with special reference to AIDS.Therapie. 47(6):503-512.

Roy, S., et al. (2006). Modulation of Immune Function by Morphine: Implications for Susceptibility to Infection. J Neuroimmune Pharmacol. 1:77-89.

Satoh, I.I. \& Mori, S. (1997). Subregional assignment of the proopiomelanocortin gene (POMC) to human chromosome band 2p23.3 by fluorescence in situ hybridization. Cytogenet Cell Genet. 76:221-222.

Schug, S.A., Zech, D. \& Grond, S. (1992) Adverse effects of systemic opioid analgesics. Drug Safety. 7:200-13. 
Scrimshaw, N.S. \& SanGiovanni, J.P. (1997). Synergism of nutrition, infection, and immunity: an overview. Am J Clin Nutr. 66(2):464S-477S.

Sharad, S., et al.. (2007). Correlation of circulatory immunoglobulin levels with $\mathrm{Mu}$ opiate receptor allele. Indian J Biochem Biophys. 44(5):394-400.

Shen, L., et al. (2006). Differential regulation of neutrophil chemotaxis to IL-8 and fMLP by GM-CSF: lack of direct effect of oestradiol. Immunology. 117(2):205-212.

Shin, K. \& Masato, K. (2008). Anesthetics, immune cells, and immune responses. J Anesth. 22:263-277.

Sibinga, N.S. \& Goldstein, A. (1988). Opioid Peptides and Opioid Receptors in Cells of the Immune System. Annual Review of Immunology. 6:219-249.

Simonin, F., et al. (1995). K-opioid receptor in humans: cDNA and genomic cloning, chromosomal assignment, functional expression, pharmacology, and expression pattern in the central nervous system. Proc Natl Acad Sci USA. 92:1006-1010.

Smolka, M., \& Schmidt, L.G. (1999). The influence of heroin dose and route of administration on the severity of the opiate withdrawal syndrome. Addiction. 94: 1191-1198.

Somaini., L, Giaroni, C. \& Gerra, G. (2008). Opioid Therapy and Restoration of the Immune Function in Heroin-Addicted Patients. Heroin Addict Relat Clin Probl. 10(4):39-44.

Sozzani, S., et al. (1995). Receptors, signal transduction, and spectrum of action of monocyte chemotactic protein-1 and related chemokines. J Leukoc Biol. 57(5):788-794.

Thomas, P.T., Bhargava, H.N. \& House, R.V. (1995). Immunomodulatory effects of in vitro exposure to morphine and its metabolites. Pharmacology. 50(1):51-62.

Vaccarino, A.L., et al. (2000). Analgesic effects of endomorphin-1 and endomorphin-2 in the formalin test in mice. Pharmacology letters. 67(8):907-912.

Vallejo, R., de Leon-Casasola, O. \& Benyamin, R. (2004) Opioid therapy and immunosuppression: a review. Am J Ther. 11(5):354-365.

Varela, P., et al. (1997). Human immunodeficiency virus infection and nutritional status in female drug addicts undergoing detoxification: anthropometric and immunologic assessments. Am J Clin Nutr. 66(2):504S-508S.

Vassou, D., et al. (2008). Opioids modulate constitutive B lymphocyte secretion. Int Immunopharmacol. 8:634-644.

Wang, J.B., et al. (1994). Human mu opiate receptor: cDNA and genomic clones, pharmacologic characterization and chromosomal assignment. FEBS Lett. 338: 217222.

Wetzel, M.A., et al. (2000). $\mu$-Opioid Induction of Monocyte Chemoattractant Protein-1, RANTES, and IFN-\{gamma\}-Inducible Protein-10 Expression in Human Peripheral Blood Mononuclear Cells. J. Immuno. 165: 6519-6524.

Yasuda, K., et al. (1994). Localization of the kappa opioid receptor gene to human chromosome band 8q11.2. Genomics. 19: 596 597.

Zabel, B.U., et al. (1983). High-resolution chromosomal localization of human genes for amylase, proopiomelanoconin, soma $\neg$ tostatin, and a DNA fragment (D3SI) by in situ hybridization. Proc Nad Acad Sci USA. 80:6932-6936.

Zoja, C., et al. (2002). Shiga toxin-2 triggers endothelial leukocyte adhesion and transmigration via NF-kappaB dependent up-regulation of IL-8 and MCP-1. Kidney Int. 62:846-856. 


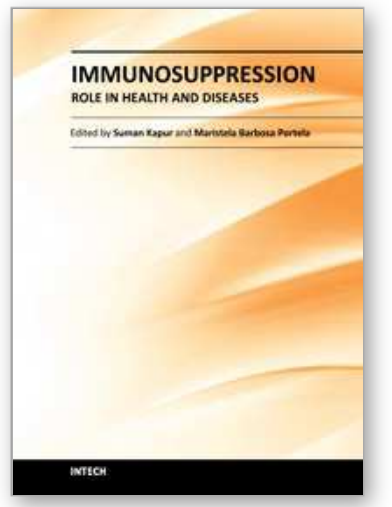

\author{
Immunosuppression - Role in Health and Diseases \\ Edited by Dr. Suman Kapur
}

ISBN 978-953-51-0152-9

Hard cover, 470 pages

Publisher InTech

Published online 24, February, 2012

Published in print edition February, 2012

A need for a book on immunology which primarily focuses on the needs of medical and clinical research students was recognized. This book, "Immunosuppression - Role in Health and Diseases" is relatively short and contains topics relevant to the understanding of human immune system and its role in health and diseases. Immunosuppression involves an act that reduces the activation or efficacy of the immune system. Therapeutic immunosuppression has applications in clinical medicine, ranging from prevention and treatment of organ/bone marrow transplant rejection, management of autoimmune and inflammatory disorders. It brings important developments both in the field of molecular mechanisms involved and active therapeutic approaches employed for immunosuppression in various human disease conditions. There was a need to bring this information together in a single volume, as much of the recent developments are dispersed throughout biomedical literature, largely in specialized journals. This book will serve well the practicing physicians, surgeons and biomedical scientists as it provides an insight into various approaches to immunosuppression and reviews current developments in each area.

\title{
How to reference
}

In order to correctly reference this scholarly work, feel free to copy and paste the following:

Suman Kapur, Anuradha Pal and Shashwat Sharad (2012). Role of Opioidergic System in Humoral Immune Response, Immunosuppression - Role in Health and Diseases, Dr. Suman Kapur (Ed.), ISBN: 978-953-510152-9, InTech, Available from: http://www.intechopen.com/books/immunosuppression-role-in-health-anddiseases/role-of-opioidergic-system-in-humoral-immune-response

\section{INTECH}

open science | open minds

\section{InTech Europe}

University Campus STeP Ri

Slavka Krautzeka 83/A

51000 Rijeka, Croatia

Phone: +385 (51) 770447

Fax: +385 (51) 686166

www.intechopen.com

\section{InTech China}

Unit 405, Office Block, Hotel Equatorial Shanghai

No.65, Yan An Road (West), Shanghai, 200040, China 中国上海市延安西路65号上海国际贵都大饭店办公楼405单元

Phone: +86-21-62489820

Fax: +86-21-62489821 
(C) 2012 The Author(s). Licensee IntechOpen. This is an open access article distributed under the terms of the Creative Commons Attribution 3.0 License, which permits unrestricted use, distribution, and reproduction in any medium, provided the original work is properly cited. 